ELORE (ISSN 1456-3010), vol. 17 - 2/2010.

Julkaisija: Suomen Kansantietouden Tutkijain Seura ry.

[http://www.elore.fi/arkisto/2_10/sarelin_2_10.pdf]

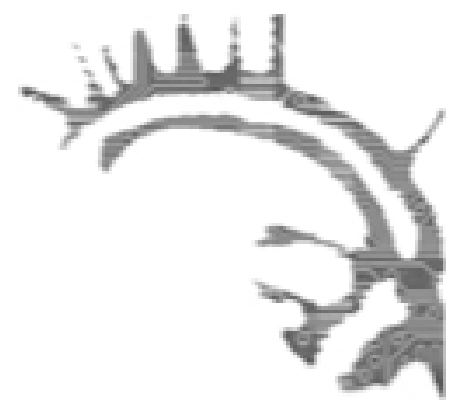

\title{
ReCENSION
}

\section{MENING GENOM (KRISTEN) METAL}

MOBERG, MARCUS 2009: Faster for the Master! Exploring Issues of Religious Expression and Alternative Christian Identity within the Finnish Christian Metal Music Scene. Åbo: Åbo Akademis förlag. 320 sidor.

\section{Mikael Sarelin}

Metal-musik har sedan barnsben förknippats med religion och religiösa uttryck. Oftast har metal varit känt för att flirta med vad som ibland kallas för den "mörka sidan", det vill säga med ockultism och djävulen. Men det finns även en annan sida av metal-musiken, en sida som kanske inte så många känner till. Det är denna, den kristna dimensionen av metal, som Marcus Moberg undersöker i sin doktorsavhandling i religionsvetenskap, Faster for the Master.

Vad är då kristen metal? Enligt Moberg bör musiken för att kunna definieras som kristen metal innehålla ett kristet budskap, låttexterna bör med andra ord vara uttalat kristna. Vidare skall musiken framföras av och för troende kristna. Och så bör det förstås vara musik som tillhör genren metal. Moberg skriver att den kristna metal-scenen i stor utsträckning har lånat attityd, stil, estetik och även musik från den icke-kristna (sekulära) metal-scenen. Attityden är med andra ord aggressiv och kompromisslös. Stilen och estetiken domineras av färgen svart, av medeltida vapen och nitförsedda kläder. Musiken är tung, nedstämd och ofta snabb till tempot, sången är antingen hög och gäll eller ett brutalt, skrikigt morrande. Attityd, stil, estetik och inte minst musik varierar enligt subgenre inom metal-musiken, som kan röra sig mellan allt från klassisk heavy metal till death metal eller rentav black metal. Samtliga stilar finns enligt Moberg representerade inom den kristna metal-scenen. Detta är dock inte rätt plats att redogöra för den sekulära metal-musiken och dess subgenrer, ifall intresse för dessa väcktes rekommenderar jag bland andra Deena Weinsteins 
Mikael Sarelin: Mening genom (kristen) metal

Heavy Metal. The Music and Its Culture (1991), Keith Kahn-Harris' Extreme Metal. Music and Culture on the Edge (2007) och Robert Walsers Running with the Devil. Power, Gender, and Madness in Heavy Metal Music (1993).

\section{SYFTE OCH MATERIAL}

Moberg granskar i sin avhandling den kristna metal-scenen i Finland som ett populärkulturellt medel genom vilket scenmedlemmarna uttrycker sin kristna tro och identitet. Hans syfte är att redogöra för den kristna metal-musiken och dess kultur samt för vilka betydelser den har för sina medlemmar. I sitt trefaldiga syfte redogör han för det första för den kristna metal-scenen genom att relatera till den sekulära metal-musikens ramverk då han beskriver den kristna metal-scenens stil, estetik, musik, låttexter och för scenens historiska bakgrund. För det andra granskar han vilka meningar och funktioner de aktiva scenmedlemmarna tillskriver den kristna metal-scenen i Finland. Slutligen granskar han processer där medlemmar av den kristna metal-scenen i Finland förses med resurser som hjälper dem att konstruera alternativa former för religiöst uttryck och en alternativ kristen identitet, det vill säga alternativa sätt att göra religion och vara kristna på.

Intervjuer med centrala medlemmar av den kristna metal-scenen utgör grunden i Mobergs material. Utöver intervjuerna har han gjort deltagande observation på festivaler och spelningar, bekantat sig med låttexter, tidningar, fanzines (amatörtidningar) samt använt diskussionsfora och annan information från bland annat artisters egna hemsidor som finns tillgänglig på internet. En aspekt som ter sig intressant i mina ögon är att Moberg har valt att inte anonymisera sina informanter. Han motiverar sitt val med att informanterna själva har beslutat sig för att framträda med sina namn och med att de är kända personer som befinner sig i nyckelpositioner inom sin scen och därför öppet står för allt som de har uttryckt i intervjuerna. Som jag ser saken är det dock alltid i sista hand forskarens ansvar, inte informanternas, att besluta huruvida informanterna behöver skyddas genom anonymisering eller fingerade namn.

I arbetet med min egen avhandling inom vars ramar jag undersöker maskuliniteter inom den finska black metal-scenen (något av den ideologiska motpolen till kristen metal) har jag valt att anonymisera mina informanter även om dessa gärna hade valt att framträda med sina namn av liknande skäl som Mobergs informanter, nämligen för att visa att de står bakom sina ideologiska val och sina åsikter. Jag motiverar mitt val att anonymisera informanterna med black metal-scenens från samhällsnormerna avvikande värderingar och på dess inte helt fläckfria rykte i det omgivande samhället, faktorer som kunde tänkas försvåra livet för mina informanter ifall jag hängde ut dem i allmänheten. Med detta vill jag dock inte ifrågasätta Mobergs val, den kristna metal-scenen, dess värderingar och rykte i samhället är trots allt helt andra är hos den scen som utgör föremål för min egen forskning. Moberg gör dock ett intressant och i en viss mån ett avvikande val då han bestämmer sig för att inte anonymisera sina informanter. 
Mikael Sarelin: Mening genom (kristen) metal

\section{TEORETISKA PERSPEKTIV}

Moberg skriver att han fokuserar på en diskursiv konstruktion av kristen metals meningar och funktioner inom en finsk social, kulturell och religiös kontext. Särskild vikt fäster han vid hur mening skapas och upprätthålls utgående från ett socialkonstruktionistiskt perspektiv, det vill säga hur individers självbild konstrueras i förhållande till och genom social interaktion, främst genom språket. Moberg granskar alltså hur identiteter konstrueras inom den kristna metal-scenen i Finland, hur medlemmarna av den kristna metal-scenen fyller sina liv med religiös mening. Genom en diskursanalytisk infallsvinkel undersöker Moberg hur anhängarna av den kristna metal-scenen uppfattar scenen och sig själva i förhållande till den. I praktiken gör han detta genom att söka efter återkommande mönster i anhängarnas berättelser, på Internet, konserter och så vidare. De två viktigaste teoretiska redskapen utgörs för Mobergs del alltså av diskursanalys och socialkonstruktivism.

Ett begrepp som redan ett flertal gånger har förekommit inom denna text och som tillsammans med ovannämnda teoretiska perspektiv utgör ett centralt verktyg för Moberg är scenbegreppet. Detta är ett begrepp som möjliggör ett granskande av samtliga aktörer inom en viss kulturyttring parallellt, i Mobergs fall den kristna metal-kulturen. Scenbegreppet omfattar för skribenten allt från artister till produktion och från distribution till fans och konsumenter. Scener bestäms och avgränsas på basis av plats, de kan vara lokalt, regionalt, nationellt, transnationellt eller globalt bestämda. Scenbegreppet i sig är inte ett analysredskap men det kan användas framgångsrikt tillsammans med ett sådant, i Mobergs fall med socialkonstruktivism och diskursanalys.

\section{BAKGRUND}

För att beskriva förhållandet mellan religion och populärkultur redogör Moberg för processer av sekularisering och differentiering i den samtida västvärlden. Religionens betydelse i vårt samhälle har inte bara minskat, hävdar Moberg, den har dessutom förskjutits mot den privata sfären. Detta betyder bland annat att den finska statskyrkan som institution har förlorat anhängare till mera privata andlighetsuttryck. Men det innebär även att populärkultur och religion allt oftare har kommit att växelverka, vilket inte minst tagit sig i uttryck genom den kristna populärmusiken. Samtida kristen musik (Contemporary Christian Music) förekommer inom alla musikaliska genrer och utgör alltså inte en genre i sig själv. Samtida kristen musik låter och ser oftast ut som sin sekulära motsvarighet, skriver Moberg, men den skiljer sig från denna genom kristna låttexter, troende musiker, samt kristna produktions- och distributionskanaler. Detta gäller i stora drag även kristen metal, vilket redan har konstaterats ovan.

Kristen metal låter och ser även i stort sett ut som sin sekulära motsvarighet, med vissa undantag. Därför väljer Moberg att ge läsaren en bild av hur den sekulära metal-scenen är konstruerad genom att granska dess historiska, visuella, estetiska och verbala dimensioner. Han redogör för metal-musikens olika subgenrer och för dess 
Mikael Sarelin: Mening genom (kristen) metal

element av motstånd och kommer också ihåg att nämna metal-musikens kontroversiella drag. Efter att ha gjort detta bakgrundsarbete redogör han för den kristna metal-musiken och dess kultur med tyngdpunkt på den kristna metal-scenen i Finland. Avsnittet om kristen metal skall enligt författaren förstås i relation till hans redogörelse av den sekulära metal-scenen. Kristen metal skiljer sig från sin sekulära motsvarighet främst genom låttexterna och bör enligt Moberg inte ses som en egen subgenre inom metal. Snarare representerar den kristna metal-scenen samtliga subgenrer som finns inom metal. Kristen metal finns inom alla eller i varje fall inom de flesta subgenrer och -stilar som existerar inom sekulär metal. De kristna metal-musikerna har alltså valt att inte skapa egna stilar att uttrycka sig genom, utan sprider hellre sitt budskap via redan existerande metal-stilar.

Låttexterna handlar enligt Moberg om vardagsproblem sedda ur ett kristet perspektiv, men även låtar som behandlar Kristi lidande, korsfästelse och offer samt apokalyptiska teman förekommer ofta såsom även låttexter om den andliga kampen mot Satan och mot synd. Många av de kristna banden flaggar med sin tro och riktar snarast sin musik till andra kristna. De strävar därför inte heller efter att sprida sina skivor på den sekulära marknaden och uppträder endast på kristna konserter och festivaler. Andra är däremot mera försiktiga med att ta på sig en kristen stämpel eftersom en sådan enligt dem kunde tänkas skrämma bort möjliga icke-kristna lyssnare. Lyssnare som, ifall det kristna inte framhävs för mycket, med tiden kunde göras mera mottagliga för det kristna budskapet.

\section{TRO GENOM METAL}

I sin analys konstaterar Moberg att kristen metal utgörs av en blandning av kristen tro och populärmusikgenren metal. Kristen metal erbjuder för sina fans ett alternativt sätt att uttrycka sin kristna tro. Den kristna metal-scenen utgör inte ett hot mot den traditionella kristna institutionen utan snarare ett komplement till den, även om det inom den finska scenen nog höjs en del kritiska röster mot de mera traditionella sätten att uttrycka sin kristna tro. Mobergs avhandling ger en intressant och välbehövlig bild av växelverkan mellan religion och populärkultur som han exemplifierar med den kristna metal-scenen i Finland.

\section{LITTERATUR}

KAHN-HARRIS, KEITH 2007: Extreme Metal. Music and Culture on the Edge. Oxford: Berg.

WALSER, ROBERT 1993: Running with the Devil. Power, Gender, and Madness in Heavy Metal Music. Hanover: Wesleyan University Press.

WEINSTEIN, DEENA 1991: Heavy Metal. The Music and Its Culture. New York: Da Capo Press.

Filosofie magister Mikael Sarelin, doktorand vid ämnet folkloristik, Åbo Akademi 